\title{
Can Conducting a Talking Circle about a Sensitive Topic Increase Participation for Elementary Aged Learners?
}

\author{
Patricia Lyons, Kaitlyn McCormack, Samantha Sauer, Michelle Chamblin \\ Molloy College, Rockville Centre, NY, USA \\ Email: mchamblin@molloy.edu
}

How to cite this paper: Lyons, P., McCormack, K., Sauer, S. and Chamblin, M. (2019) Can Conducting a Talking Circle about a Sensitive Topic Increase Participation for Elementary Aged Learners? Open Access Library Journal, 6: e5594.

https://doi.org/10.4236/oalib.1105594

Received: July 9, 2019

Accepted: August 6, 2019

Published: August 9, 2019

Copyright $\odot 2019$ by author(s) and Open Access Library Inc.

This work is licensed under the Creative Commons Attribution International License (CC BY 4.0).

http://creativecommons.org/licenses/by/4.0/

\begin{abstract}
This action research project investigated the effects of talking circles on student participation when engaging in sensitive topics. Researchers used $38-4^{\text {th }}$ and $5^{\text {th }}$ graders from two elementary classrooms. Both classrooms were located in Catholic schools. For the pretest phase, students were taught a series of controversial topics within the curriculum. To deconstruct the lesson themes, a traditional question, answer and discussion was employed. Researchers examined students' participation, the quality of questions about injustice/justice that was raised and the students' written statements about how they could make changes towards solutions. The strategy of using talking circles was implemented as a treatment. A second series of lessons concerning a controversial topic was presented. Students were directed to use the talking circle method to deconstruct themes in the lesson. Researchers again examined participation, the quality of questions about injustice/justice and students' written statements about how they could make changes towards solutions. The researchers as teachers also reflected on their behavior and participation comparing a traditional discussion to the talking circle. The implementation of talking circles increased student participation, and the level of commitment to problem solving increased. The researchers as teachers also found that using the talking circle method was a more effective tool as it alleviated the role of teacher from expert to participant and facilitator. During the talking circle treatment, students communicated their opinions with civility. Researchers concluded that talking circles was an effective method for discussing sensitive topics for the $4^{\text {th }}$ and $5^{\text {th }}$ graders in this study. This corroborates the research on talking circles which has been implemented with older populations as much of the research begins with adolescent students. This research demonstrates that the method can be effective with younger populations and be an essential aid for teachers who may have difficulty pre-
\end{abstract}


senting sensitive topics such as racism, death, gender differences, disability, immigration and slavery to younger students.

\section{Subject Areas}

Education

\section{Keywords}

Restorative Justice, Talking Circles, Culturally Responsive Education, Elementary Education, Curriculum and Teaching, Civil Discourse, Catholic Education, Inclusive Education, Student Participation, Teaching Strategies

\section{Research Rationale}

As educators, we believe the social aspect of a classroom can be more memorable and influential than just focusing on academic standards. The hidden curriculum used to build upon teachable moments can mold students' values and prepare them to become upstanding citizens in the current social climate. Although each child comes into our classroom with different views and opinions concerning different topics, it is our responsibility to create a safe environment where all students feel secure from prejudices, biases, and stereotypes. As the social climate changes each year, it becomes harder to uphold a safe environment for all students within a classroom. Racism, prejudice and biases have been root causes of many unjust acts in our immediate and global community. Each of our schools exemplifies a different diverse community, which brings up a variety of sensitive topics that need to be discussed. However, at times teachers are uncomfortable with these topics. Sometimes, this discomfort comes from a lack of information or feeling pressured to react in a particular way. In many situations a teacher might not be of the same ethnic or racial background as the students she/he is teaching. This also might make the teacher apprehensive on taking on some of these topics. If handled inappropriately, the teacher may fear to be considered prejudice, racist, or bias. This fear can then hinder these conversations.

One method we have found useful is talking circles. Talking circles has been beneficial to create conversations about literature. During these conversations, students can have opposing views, introduce new topics, and develop a format to have a conversation. We believe using the strategy of talking circles, to explore conversations about sensitive topics, will promote student participation to share and evaluate their thoughts and opinions. Students each come with their own views and legacies that they adopt from their home life which are not always the same. The use of a talking circle will start a conversation which will allow students to share different views and will generate room for empathy and change. A sense of empathy can foster a safe environment in the classroom where students' views can be equally accepted. By creating an understanding of other people's values there may be a decrease in pre-judging others and students will not rely 
on stereotypes.

The methods in this thesis manifested from the social theatre play Henry Box Brown. This empowering performance invites the audience to consider social change. The play inspired us to explore our own narrative and determine what steps we might want to take in the effort towards creating a more just community within our classroom. We want to inspire our students to become advocates in the classroom rather than continuing to be bystanders to prejudices, stereotypes, and biases within their communities. We hope each of our students take away a belief in change from this social experiment. A quote which we truly believe relates to the importance of our thesis is from Nelson Mandela, "No one is born hating another person because of his background or his religion. People learn to hate, and if they can learn to hate, they can be taught to love, for love comes more naturally to the human heart than its opposite".

\section{Action Research Question}

Can conducting a talking circle about a sensitive topic increase participation for elementary aged learners?

This research led us to propose the following questions:

1) Will fourth and fifth graders ask more specific questions about justice injustice?

2) Will the talking circle encourage the students to make statements of change?

3) Will a talking circle better equip the teacher to handle race and ethnicity discourse?

\section{Review of Literature}

\subsection{What Are Sensitive Topics?}

As a child develops, they become more conscious of events and attitudes in their society that at times can cause tension and controversy. These topics become sensitive to discuss both at home and at school, due to a variety of opinions involved and the difficulty to communicate their beliefs civilly. Sensitive topics can include controversial ideas, beliefs, or situations, "which students may have experience of or hold deeply ingrained personal beliefs about" [1]. These topics are crucially important to students' awareness of the world and its social, moral, political, and civic foundations. Sensitive topics need careful handling due to a possibility of some students becoming hurt or offended.

As facilitators of learning, it is critical to identify possible sensitive topics that can influence student's lives, as well as have an unbiased understanding of these topics. By first understanding the base definitions of these topics, people can begin to understand the variety of views related to the topic. Sensitive topics may vary widely from religion to race to death and bereavement [1]. The United States of America is often referred to as the Melting Pot, due to the diverse cultures immigrating to this country. This metaphor refers to many different races, 
religions, and cultures blending together as one. Religious beliefs vary from person to person, even within the same religion, therefore creating a vast variety of controversies within communities. People's religious beliefs also influence their views of further sensitive topics, such as abortion and marriage. Race, however, refers to groups of people who have differences and similarities in biological traits deemed by society to be socially significant, meaning that people treat other people differently because of them [2]. Research has shown that "fear is, in particular, a prevalent issue when considering research on race, at least in the United States, and many studies point to the manifestation of racial fears as a factor that affects people of all races and ages" [2]. Movements, such as Black Lives Matter, have refocused a spotlight on race and racism, which results in frequent discussions and debates related to this topic. Another common sensitive topic is death and bereavement, which unfortunately occurs within everyone's lives. The ability to understand and come to terms with death is a difficult topic not only for children, but for all adults who lose a loved one.

Sensitive topics, which are currently in the social spotlight, include sexuality, gender identity, mental health, and politics [1]. In the current society, these topics are seen in a positive and negative way based on an individual's opinion. Sexuality can be defined as a person's sexual orientation or preference. In today's society, people are able to express their true sexuality; however, people's religion and values can sometimes cause different understandings of this topic that are not always portrayed in a civil manner [1]. Similarly, gender equality has become a social movement seen throughout politics and social media, where women's rights as well as LGBTQ+ has become topics that need to be handled carefully. Social change movements, such as \#MeToo, have created a chain reaction for standing up and respecting women's rights. Unfortunately, not all human beings share the same values and beliefs, which often cause conversations of this topic to become uncomfortable and defensive. A new understanding and comprehension of the degrees of mental health has created an awareness of this topic, but unfortunately still lacks an acceptance of certain invisibles diseases. People's inability to accept mental health as an illness, creates a lack of empathy and understanding of others struggles which has a negative impact on those individuals' health. Due to a lack of acceptance towards mental health illnesses, many individuals feel neglected and an overall pressure from society to fit the status quo. This pressure and neglect can result in many outcomes, such as self-harm or suicide. Underlying many of these sensitive topics is the basis of individuals' political views. People's political views influence their decisions among a variety of topics, including basic understandings of individuals' most common basic rights. This becomes a sensitive topic as the debate or conflict among individuals or parties increases in the race to achieve power.

Due to an individual's freedom of experience and critical thinking the list of sensitive topics is infinite in correspondence with people's ideas and beliefs. While considering possible sensitive topics, it is beneficial to reflect on a quote 
by Audre Lorde, who said, "It is not our differences that divide us. It is our inability to recognize, accept, and celebrate those differences" [3].

\subsection{What Are Current Sensitive Topics for Elementary Aged Learners?}

Educators are introduced to a new class of students each consecutive year, which changes the classroom environment and dynamics. As society and social climates continue to change, facilitators of learning observe students enter their classroom with a multitude of sensitive situations, each unique to the child. Students may enter the classroom with a variety of circumstances, including changing family conditions, low self-esteem, ongoing altercations involving other students, or further matters they may be internalizing. It is the instructor's responsibility to create a relationship with each student, while facilitating a comfortable and safe environment. It is crucial to be prepared for when these topics come up in a lesson or in everyday conversation, as certain students may feel offended, defensive, or upset. Students' viewpoints on a variety of topics, "may be wrapped up in their personal identities, influenced by family members, or connected to religious/spiritual/moral beliefs" [4].

Although, "childhood is a constant evolution of emotions, behaviors, and beliefs about how the world works" [5], certain topics can be more sensitive for children than others. Sensitive topics that are relative particularly to elementary aged learner are parent separation or divorce, new additions to the family, and death of a loved one. When students experience divorce or death within the family, they may feel angry, sad, or even a sense of guilt or blame about what happened [5]. In the classroom, this could appear as difficulty concentrating in the classroom, a sense of distress, or increased anxiety [5]. Other sensitive topics include changes in routine, such as family members losing or starting a job, and moving to a new town or even country. Within the family, the individual student can be going through his or her own personal struggles, with gender identity or puberty [1]. A student's gender identity can be a difficult circumstance for a student to comprehend, and it then can radiate through as anxiety or caution within the family and around classmates.

A common sensitive topic within each classroom is discussing disabilities and mental health. This includes both students in the class living with a disability or mental health disorder, or a family member at home. In order to create a comfortable and safe environment for all students, it is important for students to understand what may make each other different or unique, and how to treasure these differences. Another topic affecting a multitude of students both directly and indirectly is immigration. Students may have family members who are undocumented, and live every day in constant fear that they will have to leave to go back to their home country. This could mean going back to difficult situations and never returning again. These topics can have severe effects on the student, how they learn, how they react, and how they behave in the classroom. 
Unfortunately, many students have experienced traumatic events that affect their lives in ways their teacher may not understand immediately. Students can be victims of natural disasters that could lead to homelessness. It is possible that students may live below the poverty line and could be homeless, moving from shelter to shelter with no stable environment other than the classroom. Other students may have experienced abuse or been a witness of a violent act that has either happened in the home or around their neighborhood [1]. This can cause the student to become anxious, scared, or react to classroom situations in a unique way. Unfortunately, there is also incidence where students may be battling cancer or another genetic disease, which not only affects the one particular student but also can take an emotional toll on fellow friends and peers. Lastly, a student may have a family member who is sick or goes through particular medical experiences which can directly affect the student not only at home but also in the classroom.

Although a child's school and classroom are commonly considered a safe haven, many times there are incidences at school that can be problematic or troubling for them. For example, fire drills, lockdown drills, and other school safety drills can become sensitive topics to discuss with students [1]. These drills may be sensitive to some students because they may have experienced a fire prior which can be recalled during a fire drill, bringing back fearful memories. These topics have a probability of instilling fear of what could happen, rather than always instilling confidence in knowing what to do. Other classroom moments including bullying, fighting, or judging, can be considered as sensitive issues that occur on the fly and can be seen as teachable moments. Particularly during the holidays, students become aware of religious differences between one another and often need guidance to understand how others can believe in different theories. As students get older the discussion of Santa Claus and the Easter Bunny come up quite often. Although these may seem like smaller moments, to students this can be seen as a breach of honesty and takes time for them to comprehend. This may be seen particularly often within Catholic schools as they may discuss these particular holidays in deeper detail. Since this thesis will be examined within two separate Catholic schools, this is a relative sensitive topic a teacher may experience.

Each of these topics can affect different children and have a unique effect on each child. These topics can appear in casual conversations among students or within a classroom lesson. As facilitators of learning, it is important to make a connection with each student and understand their values, beliefs, and background that may affect them in the classroom. It becomes the teacher's responsibility to provide ways students can openly discuss their opinions and beliefs in a civil manner, where they feel safe rather than attacked or judged [6]. These topics will be part of the teachable moments that will allow educators to create better pathways for civil discourse and communication within the classroom, which can then be used and applied in the student's everyday discussions. 


\subsection{How Do Elementary Schools Traditionally Handle Sensitive Topics?}

When someone is cornered with an uncomfortable topic, people tend to ignore and change the conversation. In schools, it is important to do the opposite, and rather address the topic in a civilly and safe manner. Educators should teach students that sensitive topics should be handled properly, and learn how to be comfortable talking about such topics. As facilitators of learning, it is inevitable that opportunities will arise where it is necessary to teach about sensitive topics [4]. These topics may range from "racism, forced labor or slavery to bullying, sexual orientation, and gender biases-and may be completely unexpected" [7]. Unfortunately, this is not always the case, and many educators continue to disregard these sensitive topics out of fear and lack of knowledge [2]. Today's world is separated, rather than working together. Society often separates people by their race, religion, gender, or economic class grouping. Race is a very serious conversation to have with students. Teachers encourage and model how students should treat everyone as equals; however, outside of school they are witnessing the opposite.

When race is brought up in a classroom, some teachers are not comfortable with going into detail about the topic. Research has shown that "honest conversations about race are likely to be both difficult and uncommon" [2]. Teachers fear the outcomes of sensitive topics, rather than encouraging students to learn from them. The Journal of School Leadership found that "Fear is, in particular, a prevalent issue when considering research on race, at least in the United States, and many studies points in the manifestation of racial fears as a factor that affects people of all races and ages in school" [2].

Educators fear rejection, tension, and offending others based on sensitive topics. A study conducted by Emily Palmer and Karen Louis found that,

"Fear of being considered racist was a barrier for white teachers and administrators that impacted collective focus on racial achievement gaps; principal's deep personal engagement over a period of several years encouraged a process of confronting and mitigating this fear, and helped teachers engage with the implications of race for school and classroom practices. Discomfort, a critical element and confronting racial inequities in schools, requires school leaders, particularly principles, to authentically participate and engage in order to foster teacher change" [2].

This research confirmed the sense of fear many educators experience when faced with confronting sensitive topics within the classroom. It also found that modeling from leadership, such as a principal, as well as experience and training, helped to promote educators to address these topics within the classroom with more confidence.

When a student feels uncomfortable, they tend to put a shield up, and will not commit to the lesson or activity being taught. Teachers steer away from these topics at times to avoid these student reactions. When sensitive topics are 
brought up, the atmosphere is shifted. It is a teacher's duty to bring the conversations into a discussion when addressed, and encourage students to learn and live with the positive outcome of bringing up such relative topics of today's world. Teachers must manifest safe and comfortable classrooms for their students, which includes the process of conducting civil, respectful, and open conversations.

\subsection{How Do Educators Prepare for Teaching Sensitive Topics?}

Students deserve to be taught about these sensitive topics in authentic, engaging, and purposeful ways. Educators report that "freedom of expression, critical thinking, the scrutiny of evidence and underlying assumptions are all highly valued in the academic environment and we need to support our students to develop the skills associated with these by facilitating and encouraging reasoned and balanced discussions" [1]. During this discussion, "it is not uncommon for students to express a viewpoint which is likely to be controversial and distressing to others but remains unchallenged by the group" [1]. It becomes the teacher's responsibility to facilitate a balanced and reasoned discussion, without censoring their viewpoints. In order to accomplish this task, students must first learn the appropriate skills to communicate their viewpoint in a clear, sound, and respectful manner. While developing these skills, it is appropriate for teachers to "provide discussion and interaction opportunities on an issue which is less sensitive but controversial enough to enable 'a trial run' by problematizing an issue and promoting a balanced discussion" [1].

There are eight important steps and components teachers utilize while developing a stable and comprehensive discussion about a sensitive topic. The first step is to set the stage by developing rules to be enforced throughout the discussion. These rules may include waiting for others to complete their point before talking; do not ridicule other people's opinion, or put them down; criticize ideas, not individuals; avoid blame and speculation; and avoid inappropriate language [8]. The next step is for the educator to reflect on his or her own biases about the topic prior to the discussion. Before being able to comprehend and facilitate a class discussion about a topic, educators must first understand "any areas of personal discomfort that might occur for [the teacher] when facilitating" [1]. Once a teacher reflects upon his or her own beliefs and biases, it is his or her responsibility to recognize and consider the diversity of the class. Alicia Moore and Molly Deshaies state that "it is important to remember that each of the students in your classroom comes from a unique background and has had different experiences" [7]. In order to keep students engaged and focused upon a single topic, it is crucial to identify a framework and objective for the discussion. Researchers, Moore and Deshaies report that this provides students with opportunities to "engage in experiences that develop fair-mindedness, and encourage recognition and serious consideration of opposing points of view, respect for well-supported positions, sensitivity to cultural similarities and differences, and 
a commitment to individual and social responsibility" [7]. Throughout this experience, educators should be prepared to foster civility from beginning to end, to ensure students do not feel personally attacked. During this time, the teacher should be prepared to deal with tense or emotional moments, by remaining calm and turning tense moments into learning experiences [7]. As the discussion of this specific sensitive topic concludes, it becomes the facilitators' responsibility to summarize and reflect about the viewpoints shared, as well as the content discussed.

It can be difficult to address concerns and issues with families. Educators should "take time to think about topics-perceptions, reactions, experiences, and impact" before discussing sensitive topics with them [9]. This will help teachers know how to approach issues, what support and suggestions that the teacher can provide, and how to increase the family's comfort and openness to discussing sensitive topics. It is important to first consider how a family may consider the teacher's role, as well as how a family's culture influences their expectations for their child. Other influential aspects include considering the "educational background and financial resources of families" [9]. By considering these components, facilitators of learning can "tailor [their] approach for addressing sensitive topics so that you create an open and comfortable atmosphere and stronger partnerships" [9].

\subsection{What Is a Talking Circle?}

The main strategy this thesis will focus upon is the use of talking circles to increase participation during discussions based on sensitive topics. A talking circle is "a simple structured process of communication that helps participants reconnect with a joyous appreciation of themselves and others" [10]. It is a carefully constructed, intentional dialogue space with the intent to "engage in a sharing of authentic personal reactions and feelings that are owned by each individual and acknowledged by others, without judgement or condemnation" [11]. The main objective of a talking circle is to "create a safe space for all voices and to encourage each participant to step in the direction of their best self" [10]. It creates an environment where individuals feel connected and respected. This strategy can be used with any age group from kindergarten to adults as long as the language and material used is developmentally appropriate.

The theory of talking circles is broken into six groups that are relevant to understanding the power of a talking circle, particularly in schools. The first theory is the "whole-child approach, which draws attention to the importance of social emotional learning" and "intentionally seeks ... to provide space for emotional, social, and moral development alongside the mental and physical" [10]. This theory focuses on understanding the role of "character and emotion in academic achievement, resilience in the face of adverse life events, and successful transitions to healthy adulthood" [10]. This opens educators' eyes to the importance of non-cognitive factors, while at most times tend to primarily depend on cognitive 
factors in a student's life. Although a student's cognitive abilities are vital to academic achievement, an individual's emotional habits of "persistence, optimism, grit, focus, and curiosity" can be more influential in predicting a person's success through transitions towards and throughout adult life [10].

The next theory focuses on the importance of relationships in human development and in the process of cognitive and social learning. This identifies that talking circles are a process to help build relationships, by strengthening trust and empathy between individuals, which ultimately is "beneficial to lifelong cognitive and social learning" [10].

The third theory of talking circles discusses a whole-school approach, which highlights "the importance of a safe school climate, a sense of belonging, and a connectedness among students in a school community". This includes the use of civil discourse, and an overall understanding of how individuals should be treating one another in a respectful manner. Researchers Boyes-Watson and Pranis state that talking circles are a "space designed to promote a sense of belonging; to cultivate awareness and consideration of others; and to ensure respectful democratic participation of all members of the community" [10].

The theory of talking circles also explores the concept of positive discipline, which seeks to use conflict to create an opportunity to enhance positive relationships within a classroom and school. This theory promotes accountability, responsibility, and ownership of harmful actions as well as initiates an opportunity to discuss the situation and possible solutions.

Next, the use of talking circles also is generated from the theory of a trauma-sensitive environment within schools. It is vital for facilitators of learning to be aware of trauma or adverse childhood experiences that students may have encountered and how that can directly affect a child's ability to create relationships and grow. Researchers Boyes-Watson and Pranis assert, "that trauma theory helps to reframe academic challenges and student misbehavior, so educators and other support staff can offer support and guidance rather than punishment as a response to student misconduct" [10]. At times, a student's search for connection and support can come in the form of misbehavior, although the child may be looking to be recognized, heard, respected, or valued. A trauma-sensitive learning environment is crucial to the success of talking circles because it allows all individuals to feel appreciated, emotionally and physically safe, and supported.

Lastly the final foundational theory describes the practice of mindfulness within the structure of talking circles. Researchers have found that talking circles are "a mindfulness practice because it encourages participants to slow down and be present with themselves and others" [10]. This practice also directly benefits the quality of attentiveness and focus with a classroom.

Although the structure of talking circles can differ within each community or even between topics, there are certain structural elements that are essential. Essential elements of constructing a talking circle include seating all the partici- 
pants in a circle, mindfulness moment, opening, centerpiece, talking piece, identifying values, generating guidelines based on the values, guiding questions, agreements, and a closing. These talking circles also include the use of a sequential or non-sequential format. A sequential format is when "one person speaks at a time, and the opportunity to speak moves in one direction around the circle" [12]. This format maximizes the opportunity for quiet voices because it forbids back and forth arguments. A non-sequential circle is more freely structured as it proceeds from one person to another with no particular order. The format is decided based on the topic, environment, and facilitator of the discussion.

\subsection{What Is the History and Evolution of Talking Circles?}

Talking circles have evolved throughout history, originating from the indigenous people, the original inhabitants of the great plains of North America, who used talking circles throughout their culture [11]. They used talking circles to communicate about life events, as well as for healing. The talking circles were based on the values of sharing, respect, and honor. The indigenous people believed talking circles were safe, secure spaces where people from the community could come and share their thoughts and feelings. Topics that were often explored during these sessions included heritage, relationships, challenges, stressors, and strengths.

In the beginning, the indigenous people would start their session by smudging the area and the members, symbolizing purification. Purification is the process of making something spiritually or ceremonially clean. Next, they had a moment of silence to honor those who had moved on, or who were struggling with health-related problems and issues. The Facilitator or the group leader would then begin with recognition of the sacred directions. The sacred directions would vary from tribe to tribe. The talking circle would then begin by opening the discussion with the passing of a feather from member to member. The feather symbolized a talking stick, this means anyone holding the feather was allowed to talk. This helped facilitate communication within the circle so each person was heard as it was passed, and forbid others from speaking over each other. If someone within the circle didn't want to speak, they simply would pass the feather to the next person within the circle [11].

Once the feather went around once, the talking circle would become an open discussion for people to address any concerns or questions to the group. This discussion was said in honor, which helped one another feel comfortable with discussing relevant problems and solutions. This time was not for criticism or debates, which kept the circle very calm and understanding. To end each talking circle, there would be cultural discussions focusing on information pertaining to tribal activities, important announcements, speakers, and/or heritage [11]. The results of these talking circles found that "circles enhance the participation of every group member, thus promoting egalitarianism" [13]. These early talking circles among Native Americans confirmed that "talking circles create a sense of 
community and closeness so that participants feel comfortable, supported and safe disclosing their feelings" [13].

Since talking circles are "a simple yet powerful Native American tradition that we have found useful in various settings" they have become a popular discussion strategy among committees, support groups, and classrooms [14]. Talking circles used in today's society do not always follow the traditions, but the act of sharing is always the same. Talking circles now are divided into four parts including building connections, piercing the surface, delving deeper, and reflecting and learning [13]. Using talking circles in the 21st century help counselors, teachers, students, and others looking for support have a chance to share their thoughts and opinions in a safe, stable, and civil group discussion. From what started as a cultural movement has now been used in therapy sessions, problem-solution discussions, classroom lessons, business meetings, and many other environments.

\subsection{How Are Talking Circles Used in a Classroom?}

The first priority of schools is to create a safe, stable environment to help care for students. For this reason, schools need to be centers of stability, continuity, and community for each student, particularly since for some students it may be their only source for this. Talking circles help fulfill these needs by providing open, civil lines of communication between peers and educators. Talking circle are "helpful for building and maintaining a healthy community in which all members feel connected and respected" [10]. This instructional strategy can be used with any age group as long as the material and language are developmentally appropriate. For example, starting at a young age, early childhood classes have students come together and work on circle time, during morning meetings, share and tell, and group discussions. Circle time is also called group time, which refers to any time that a group of people are sitting together for an activity involving a whole class discussion [10]. It is a special time to "share finger plays, chants and rhymes, songs, play rhythm instruments, read a story, and participate in movement games and relaxation activities" [15]. This first experience with talking circles helps create the fundamental abilities of communicating with peers without speaking over one another. Talking circles in the elementary level helps all learners in a variety of ways. Based on a 4th grade teacher's experience with talking circles, Christopher Rogers, has seen many different positive effects from them [16]. One way includes giving the students a chance to explore a topic before he introduces it to the class. The talking circles also give the students a chance to explain the lesson from a child's perspective rather than an adult. This also allows the quiet, timid students an opportunity to speak up and allows the higher-level learners a chance to take a leadership role as a discussion facilitator. The talking circles also encourage positive communication throughout the classroom by creating friendships, and a stronger class bond among students [16]. 
Talking circles are also a beneficial tool to use beyond the classroom, even with adults in the workplace or social environment. This is evident from the after show workshop conducted with the social change musical Henry Box Brown (Instagram: henryboxbrown_themusical). Researchers for this paper attended the musical and participated in the after show workshop. This workshop included participants starting from age 18 to senior citizens. A talking circle was conducted to express participants' feelings and thoughts based on the social change play, as well as a variety of statements about racism, stereotypes, and biases within society. It was stated that the environment was a safe place and that all opinions were welcomed and valid. The researchers for this paper were then trained to become facilitators and assisted in two after show workshop for the musical when it performed at the Madison Theatre, Molloy College. This experience led the researchers of this paper, who are teachers in training to bring this model to the elementary classroom. As in line with the research this primary experience in using talking circles, demonstrated the positive and effective outcomes from this instructional and communicational strategy. This workshop confirmed that "while the language may vary to be developmentally appropriate, holding certain conversations in a circle is equally beneficial for all members of the school community, from the youngest to the eldest" [10].

In today's society, talking circles are important to help students understand and reflect what is occurring or present around them. Talking circles can help students discuss difficult situations in their lives, as "this is happening at a time when worsening social and economic conditions in many communities result in more children coming to school sorely in need of adult support and guidance" [10]. The school community could be a student's number one source of support, stability, and dependence. It is truly important for the school community to be supportive with all kinds of students. Boyes-Watson \& Pranis state that "for public education to serve as the great equalizer in our society, it is essential that success be possible for all children, including those from the bottom of the social scale as well as those in the middle and top" [10]. The use of talking circles opens up a different type of communication and helps encourage change within social and emotional difficulties. Howard Gardner suggests that we need to "reflect deeply on the minds or intelligences we are seeking to cultivate within our educational institutions" [10]. During this process, educators encourage students to apply what they have learned in the classroom into the homes and communities of the students. Each small act of change from a student can create a chain reaction as students apply the values and communication guidelines used or discussed during a talking circle.

\subsection{What Is Civil Discourse?}

In today's society, each individual has their own viewpoint on a variety of topics, which at times can be controversial. It is hard to decipher what viewpoints may be right and wrong, but it is pertinent to listen to both sides of a controversy 
prior to formulating a personal opinion of a topic. As previously stated, students' viewpoints on a variety of topics, "may be wrapped up in their personal identities, influenced by family members, or connected to religious/spiritual/moral beliefs" [4]. Although student's may have experienced times when they were told their opinion is not valid or accepted, a school environment is a safe haven where students are able to share their opinions in a respectful and appropriate manner. However, with so many different opinions being heard in the classroom in can possibly cause controversies, and educators must facilitate a way to protect students' voices. This means "that it is also possible for schools to become places of intolerance and fear, especially for students who voice minority opinions. Schools must work to be sites of social transformation where teachers and young people find ways to communicate effectively" [17]. To effectively have respectable conversations and discussions, teachers introduce students to the guidelines of civil discourse. Civil discourse "demands that democratic participants respect each other, even when that respect is hard to give or to earn. Democratic societies must be societies where arguments are tolerated and encouraged, but this is not always easy" [17].

To effectively practice civil discourse, it is important to set guidelines that will discourage possible negative outcomes. Such guidelines can include: give people time to make their point; do not interrupt; do not ridicule other people's opinion, or put them down; consider the effect what you are saying may have on other people; listen to and consider other people's opinions; be aware that body language as well as what you say can affect others; criticize ideas, not individuals; commit to learning, not debating; avoid blame and speculation; avoid inflammatory language [8]. The teacher can put the guidelines in words in which the class will understand and provide a visual of these rules within the classroom. The students can provide suggestions when formulating these guidelines.

As researcher, Kate Shuster discusses, there are certain guidelines that a facilitator of learning can use in their classroom to ensure smooth discussions [17]. They include: "choose limited, achievable goals; intersperse discussion with other activities; establish ground rules; give everyone something to say; pay attention to classroom layout; build in debriefing sessions; don't just teach—train". It is important to create goals to ensure that the students are focused upon a single topic. The students should also be given time to prepare for the discussion, with an outline of their ideas. As discussed, prior it is important to set guidelines, so the student know what is expected of them. Every student should be given the opportunity to speak during the discussion. By using a talking circle, this mandates that each student has a personal time where each can vocalize their opinions following the guidelines they formulated as a class. The classroom layout is important because students should be able to see and hear each other without having to move, which is a positive to the circle formation used in talking circles. The teacher should offer opportunities for students to take a leadership role and contribute to the process of the discussion and offer feedback afterward. After a 
discussion, the class should come to reflect on how the discussion went and what they can do better for next time. Lastly, students should apply what they have learned about how to have civil discussions throughout different lessons. Just like writing and reading, good conversation and discussion will come with practice and modeling from the teacher and peers.

If educators practice and incorporate civil discussions into daily teaching, then it will allow students to feel more comfortable in the classroom. As students feel more comfortable in classroom discussions, this can directly affect their participation within the classroom. Through this process, students will comprehend that is acceptable to have different opinions from peers on different topics. Students will also know how to respectfully disagree or agree with someone without causing an argument. If educators can instill this knowledge into students, then they are paving the way for a brighter future as students acquire better communication skills.

\subsection{Why Is This a Beneficial Strategy for Elementary Aged Learners?}

A talking circle is a "powerful tool for that basic community function of working out how we are going to be together, which includes building relationships, establishing norms, and working through differences" [10]. This beneficial strategy promotes connection, understanding, and dialogue in a group, which ultimately encourages a safe environment for all individuals. By fostering a safe environment within the classroom, a facilitator of learning creates a healthy balance between individual needs and group needs. This strategy of talking circle provides students with values and techniques they can apply outside of the talking circle in outside interactions. The underlying philosophy of talking circles can be used a regular practice in the community, as individuals' practice "basic ways of being that are fundamental to being successful together" [10].

Students learn and develop many fundamental values through the use of talking circles including respect, equality, empathy, responsibility, self-regulation, problem solving, and leadership. Respect is highlighted as each individual's perspective is values as meaningful, and has the right to be heard. Respect is modeled throughout a talking circle by creating foundational guidelines where "each voice is given an opportunity to speak, and each person is listened to with focused attentiveness" [10]. By discussing the rules of civil discourse, students learn to respect one another's right to speak, as well as others' right to their own opinions. Equality is encouraged by promoting the concept that no one is more important or has more power than anyone else. This value is also visible in the relationship between educators and students during a talking circle because everyone has the same foundational expectations.

One of the most empowering values individuals develop through the use of talking circles is empathy, which is an individual's overall ability to connect and recognize others emotions. During a talking circle, "there is a greater opportu- 
nity to reflect on what you are feeling and to talk about your feelings than in normal conversations" [10]. Throughout this practice, problem solving skills are necessary to identify ways to listen and respect others differing views, as well as ideas of controversial topics. Each participant of the talking circle has a responsibility for their words and actions, as well a sense of ownership over your reactions and behavior throughout the discussion. Talking circles involve a necessary level of self-discipline as "participants must wait to speak, listen without responding immediately, and delay their need to speak" [10]. This is an unusual concept for most students at first, since it not how many may be used to communicating, but are crucial foundational skills towards learning to effectively communicate with others. This promotes both self-regulation and self-awareness. Lastly, talking circles "allows the gathering of differences, holds space for multiple perspectives, and recognizes the existence of multiple truths" [10]. As this develops within the talking circle, each participant becomes a leader in this practice of "fundamental democracy in which all voices are heard and all interests must be treated with dignity" [10].

\subsection{What Is Participation and How Might It Appear within a Classroom?}

Before a facilitator of learning can increase participation in the classroom, it is vital to first comprehend what participation primarily is and how it may appear within the classroom. Student participation is defined as the extent to which students participate or involve themselves in an activity, class, or course. The traditional notion of participation involves "being vocal and active within the classroom by answering and asking questions and by participating in class discussions [or] activities" [18]. The purpose of participation is to promote students to actively "absorb, seek and apply the skill and knowledge shared in the classroom or other learning activities" [19]. To create an effective learning process, there needs to a stimulating classroom environment with two-way interactions between teachers and students. Active participation is an important component to ultimately "refine and cultivate critical thinking and communication skills" [18].

Participation is often generalized with discussion, specifically in a whole class setting. However, it is crucial to remember that participation can be either passive or active. Passive participation may include sitting quietly, taking notes, listening, and carefully following the teacher's instructions. Active participation is identified when students raising their hands, ask questions, give opinions, and answer questions posed throughout a lesson. This thesis aims to focus on increasing active participation during each talking circle, encouraging students to create a safe environment where students feel comfortable to share their opinions, ask questions, and provide feedback to one another. Researchers, Abdullah, Bakar, and Mahbob stated that "to be active learners, whenever in the classroom, students must engage actively by playing the roles of information seekers" 
[19]. Students can be information seekers by developing questions related to the topic, asking for clarification when confused, giving an opinion, and listening carefully to others opinions or ideas.

Participation is an important factor "in students' academic achievement and in increasing interest and motivation in the learning process" [20]. Abdullah, Bakar, and Mahbob also expand upon this topic, discussing that many variables influence students' participation in the process of learning [19]. These variables include the students' personalities, traits and skills of the instructor, perceptions of fellow students, and overall size of the class. Students' personalities can affect participation within a classroom based on student's level of self-efficacy, which can "enhance their confident level to become more active and speak more in the classroom" [19]. In comparison, certain students become passive learners "due to the self-limitations, such as cannot focus during lecture or learning time, fear of offense, low levels of self-confidence, ... fear of failing to show their intelligence, fear that their answers will be criticized by the lecturers and the feelings of confusion" [19]. It becomes the educator's responsibility to understand the individual class dynamics and create a cohesive classroom environment to eliminate certain fears. When an educator is supportive, understanding, approachable, and open-minded, students feel more motivated to participate freely without the pressure of being criticized. Lastly, Abdullah, Bakar, and Mahbob's research found that class size can affect participation rates, since " $90 \%$ of students felt that they prefer to participate in discussions in small group as compared with in bigger classroom" [19]. A facilitator of learning should consider each of these variables while creating the flexible, safe environment for students and when considering possible strategies to increase students' participation.

\subsection{What Is the Project Zero: See, Think, Wonder Strategy?}

Project Zero was founded by philosopher Nelson Goodman at the Harvard Graduate School of Education in 1967 to study and improve education in the arts. Goodman believed that arts learning should be studied as "a serious cognitive activity but found that the general communicable knowledge about arts education was zero" [21]. Goodman therefore gave the project its name "zero" since that's where it was starting. The origin of Project Zero started with a focus on the arts, then moved to a focus of problem solving, critical thinking, and brain organization, then moved to look at multiple intelligences. In the 1990s, there was a conference to meet with many researchers and educators to explore pressing questions in education. Today, "Project Zero is an intellectual wellspring, nourishing inquiry into the complexity of human potentials-intelligence, understanding, thinking, creativity, cross-disciplinary and cross-cultural thinking, ethics-and exploring sustainable ways to support them across multiple and diverse contexts" [21]. One of the Project Zero thinking routines is See, Think, Wonder. This routine "helps students make careful observations and develop their own ideas and interpretations based on what they see" [21]. During this 
thinking routine, students are asked what is it that they see, what they think, and what they wonder about a visual image. This routine can help students distinguish between observations and interpretations, while also encouraging students to open their minds to new ideas and form new connections [21]. Teachers often use this thinking routine as an introduction to capture students' engagement as each student has the opportunity to participate with even the smallest detail. While conducting a See, Think, Wonder exercise, students will become more engaged in the topic at hand, even if they do not have any background knowledge on the topic.

During the methodology of this thesis, the post-test lesson will use a See, Think, Wonder to introduce the book, Henry's Freedom Box, to the class. The researcher will ask them the questions: What do you see?, What do you think?, and What do you wonder?. This activity will first ask students to look at the illustration on the cover and identify what they see. Next students will consider what they think is happening or what they think will happen during the book. Last the students will predict what they imagine the character on the cover may be feeling, doing, or what the focus of the book will be. The intent is that the students will become curious about the class discussion topic and consider it throughout the read-aloud of the book.

\section{Methodology}

\subsection{Participants}

This project took place at St. Brigid/Our Lady of Hope Regional School, Westbury, New York, USA in a fifth grade classroom and Holy Family School, Hicksville in a $4^{\text {th }}$ grade classroom. The students in the classroom are very diverse with many identifying as African-American, Haitian-American, Jamaican-American, Afro-Caribbean, Latino, and Caucasian. Two of the researchers for this project are full-time teachers at these locations and were afforded permission to execute the project.

\subsection{Procedure}

The pre-test of this action research study was constructed of four main components including an introduction to the topic, a period of direct instruction, a class discussion, and student assessments. One form of assessment used during this research was a frequency chart. Throughout the lesson, the teacher kept tallies on the frequency chart for the number of times students raised their hand, shared an opinion related to the topic, asked to leave the room, made an inappropriate comment, made a connection to the topic, and any time the teacher had to pause the lesson to redirect the class. The pre-lesson began by evaluating what prior knowledge and/or any misconceptions students may have had about Columbus Day, why people celebrate this holiday, and how the holiday was created. The lesson utilized direct instruction to inform students of Christopher Columbus and his initial journey to find the Indies, how Christopher Columbus 
took over land from the Native Americans, who prior occupied land of the United States, and that Americans celebrate Christopher Columbus Day because Americans still credit him with the discovery of the United States Territory. This teacher-directed method used straightforward, explicit teaching techniques to inform students about this sensitive topic, prior to having a class discussion about students' newly formulated opinions and viewpoints of Christopher Columbus. While discussing their opinions and emotions, students debated the two sides of this topic.

Lastly, students were assessed through the use of a student survey, which supplied qualitative data to support this action research study. Students completed a survey, measuring student's understanding, emotional connection, engagement, and interest in the circle discussion. Students responded to statements using a scale from strongly agree to strongly disagree. One question also asked students to identify any emotions they felt throughout the lesson. The students were also asked to construct a pledge or statement of change of how they could make a positive impact on their community related to the class discussion. Students were notified they will receive their pledge back at the end of the school year to check if they accomplished their goal. Students also were able to observe the variety of quotes for inspiration or supporting evidence. This pledge was evaluated using a 12-point rubric. Lastly, teachers will complete a reflection of the lesson. The teacher will also reflect on student's participation, engagement, and interest during the circle discussion. The teacher included both self-to-text connections as well as any connections shared by students. The reflections also included what students took away from the lesson and was visibly applied in day to day life.

For the post-test of this action research study, the educators utilized a talking circle instead of direct instruction strategies to inquire if doing so would increase participation among elementary aged learners. Throughout the lesson, the teacher once again kept a frequency chart about the number of times students raised their hand, shared an opinion related to the topic, asked to leave the room, made an inappropriate comment, made a connection to the topic, and any time the teacher had to pause the lesson to redirect the class. To begin this lesson, the teachers applied a Project Zero protocol known as "See, Think, Wonder" to introduce students to the book, Henry's Freedom Box written by Ellen Levine. This protocol asked students to identify what they see on the cover image, what they think may occur, and what they wonder about the book. As the teacher read Henry's Freedom Box to the class, students focused on the emotions and feelings of Henry, his family, and other slaves throughout the story. After students listened to the story, the lesson evolved into a talking circle discussion based on the how the acts of racism, prejudice, and stereotypes made Henry feel, and how students could make a positive change to decrease the chances of others in their community feeling the same way as Henry.

This class discussion began by stating that Henry Box Brown used vitriol oil to create a reason for him to miss work without being suspicious. Students were 
informed that vitriol oil is a strong acid that burns down to the bone and that the same way Henry felt pain, people who face prejudice, bias, and stereotypes feel this pain as well. Students were then asked to share what emotions they think of when considering situations similar to this and how they would feel. As students mentioned each emotion, the teacher dictated them onto the Smart board or whiteboard. Next, the students discussed how a chain reaction of small acts of kindness can create a larger social change. Students were asked, "What is something you can do to lessen or take this pain away?" and "How can we replace these negative feelings with positive actions?". After the teacher modeled an example, students were invited to go up and cross out one negative feeling, as they stated a positive change they could make. The students discussed that change can only happen one small act at a time, as they believe in themselves to make a positive change. As the teachers read multiple quotes related to social change, the students used that time to brainstorm one pledge they could make to create a positive change on their class, school, community or society.

Similarly, to the pre-test lesson, students completed a student survey and pledge cards to assess their knowledge and connections made to the post-test lesson utilizing a talking circle to increase participation. Students first independently completed their pledges, or statements of change, including what they would do to make a positive change in the world, how they would make it happen, and why it matters to them. Students were again notified they would receive their pledge back at the end of the school year to check if they accomplished their goal. Students once again observed a variety of quotes for inspiration or supporting evidence. Next, students completed the post-test survey focused upon students' reactions to the talking circle. Students responded to statements using a scale from strongly agree to strongly disagree. One question also asked students to identify any emotions they felt throughout the lesson. Last, the teachers completed a second reflection of the post-lesson. The teachers reflected on students' participation, engagement, and interest during the circle discussion. The teacher included any self-to-text connections as well as any connections shared by students. The teacher also reflected on what students took away from the lesson and was visibly applied in day to day life.

\section{Results}

After a period of five weeks and based on careful analysis of the data, the action research study's primary question was proven to be credible and valid. Specifically, the data indicated the following: By conducting a talking circle about a sensitive topic, it increased participation for elementary aged learners.

After conducting this action research study, each assessment conveyed significant findings to support the primary and sub questions. The most significant results were represented through a frequency table conducted during the preand post-lesson discussions. This frequency table illustrated the number of times students raised their hand, asked to leave the room, asked a question based on 
the discussion, provided an opinion about the topic, made an inappropriate response, and any occasions when the teacher paused the lesson for redirection. Based on the results, the frequency chart shown in Figure 1 shows a higher frequency of student participation behaviors during the talking circle when compared to the teacher directed lessons on sensitive topics.

The next assessment used during this action research study was analyzed through a secondary frequency chart illustrating the different emotions students felt throughout the pre- and post-test discussions. When given a survey, the students were asked to self-reflect on the emotions they exhibited throughout each lesson. The list of emotions was as followed: angry, motivated, inspired, uncomfortable, confused, bored, surprised, forgiving, guilty, excited, disgusted, and overwhelmed. Based on the results shown in the frequency chart in Figure 2, there was a significant change in a variety of emotions from pre-test to post-test, such as feeling motivated, inspired, and excited. The positive increase in these emotions supports the primary question of this action research study that elementary aged learners will be more engaged and motivated to participate in a talking circle about sensitive topics. This is also supported through the decrease of certain emotions, such as feeling bored, and confused, from the pre-test to the post-test.

The finding in this action research study resulted from questions two through eight on the student survey completed after the pre- and post-test lessons. The results from the student survey showed that students felt safer to engage and connect with the sensitive topic during the talking circle rather than the teacher-centered lesson. Based on this eight-question survey, students on average positively changed their responses after the post-test compared to their responses on the pre-test. The chart in Figure 3 assesses the students' levels of agreement ranging from strongly agree to strongly disagree for questions two to eight. This result is noteworthy and based on the sub-questions of the action research project which states that fourth and fifth grade students will ask more specific questions about injustice; and that talking circles will encourage students to make statements of change. For example, as seen in Figure 3, students felt safer in their environment based on question number three that shows $34 \%$ strongly agree during the pre-test compared to $66 \%$ percent strongly agreed post-test. It is even more important that $0 \%$ disagreed or strongly disagreed after the post-test. Question four of the survey about focus, encouragement, and participation also supports the primary question of this action research study based on the information that $20 \%$ strongly agreed compared to $79 \%$ strongly agreed post-test.

For the next pre- and post-assessment, students were asked to write a pledge card to explain how they would make a change in the world. Students were then assessed based on a twelve-point rubric, the results are shown in Figure 4. There was a positive shift happening between the pre-assessment scores and the post assessment scores. There were four students who scored a 4 out of 12 on the 
pre-assessment then scored a 12 out of 12 on the post assessment. That raised their score from 33 percent to 100 percent. This shows that students felt that it was easier to include more detail in the post-assessment than the pre-assessment. This could be based off the fact that students felt more comfortable to write about this topic because it was more interesting to them. The students' pledges in the post lesson showed that they had a better understanding of the sensitive topics within the world and were inspired to promote equality within their classrooms and community. This significantly supports the primary question of this action research study, as well as the second sub-question that talking circles will encourage the students to make statements of change.

\begin{tabular}{ccc}
\hline Number of times students ... & Pre-Test & Post-Test \\
Raise their hand & 51 & 178 \\
Ask to leave the room & 12 & 6 \\
Ask a question based on the discussion & 17 & 33 \\
Provide an opinion about the topic & 18 & 8 \\
Make an inappropriate response & 4 & 5 \\
Teacher pauses lesson for redirection & 21 & \\
\hline
\end{tabular}

Figure 1. Participation frequency table. This frequency table represents the data collected from the pre- and post-test class discussions. Tallies were taken throughout the lesson for each class and then used cumulatively. The data is based off of a total of 38 students.

\begin{tabular}{ccc}
\hline \multicolumn{2}{c}{ How would you describe how you felt during our discussion? } \\
\hline Emotions During Lesson & Pre-Test & Post-Test \\
\hline Angry & 17 & 13 \\
Motivated & 2 & 15 \\
Inspired & 2 & 27 \\
Uncomfortable & 15 & 13 \\
Confused & 18 & 6 \\
Bored & 7 & 3 \\
Surprised & 27 & 18 \\
Forgiving & 3 & 12 \\
Guilty & 3 & 9 \\
Excited & 2 & 6 \\
Disgusted & 18 & 10 \\
Overwhelmed & 3 & 11 \\
\hline
\end{tabular}

Figure 2. Emotions frequency chart. This frequency chart represents the data collected from survey question number one, which asked students to self-reflect of the emotions exhibited throughout the pre- and post-test discussion. Students could select an unlimited number of emotions, but had to select at least one. This data was based off a total of 38 students. 


\begin{tabular}{|c|c|c|c|}
\hline Question \#. & Level of Agreement & \begin{tabular}{c|c|} 
Pre-Test \\
$\%$ of Responses \\
\end{tabular} & $\begin{array}{c}\text { Post-Test } \\
\% \text { of Responses } \\
\end{array}$ \\
\hline \multirow{5}{*}{2} & Strongly Agree & $34 \%$ & $63 \%$ \\
\hline & Agree & $26 \%$ & $21 \%$ \\
\hline & Undecided & $11 \%$ & $8 \%$ \\
\hline & Disagree & $13 \%$ & $0 \%$ \\
\hline & Strongly Disagree & $16 \%$ & $8 \%$ \\
\hline \multirow{5}{*}{3} & Strongly Agree & $34 \%$ & $66 \%$ \\
\hline & Agree & $37 \%$ & $13 \%$ \\
\hline & Undecided & $8 \%$ & $21 \%$ \\
\hline & Disagree & $5 \%$ & $0 \%$ \\
\hline & Strongly Disagree & $16 \%$ & $0 \%$ \\
\hline \multirow{5}{*}{4} & Strongly Agree & $28 \%$ & $79 \%$ \\
\hline & Agree & $24 \%$ & $8 \%$ \\
\hline & Undecided & $21 \%$ & $13 \%$ \\
\hline & Disagree & $16 \%$ & $0 \%$ \\
\hline & Strongly Disagree & $11 \%$ & $0 \%$ \\
\hline \multirow{5}{*}{5} & Strongly Agree & $50 \%$ & $32 \%$ \\
\hline & Agree & $16 \%$ & $37 \%$ \\
\hline & Undecided & $18 \%$ & $29 \%$ \\
\hline & Disagree & $11 \%$ & $0 \%$ \\
\hline & Strongly Disagree & $5 \%$ & $2 \%$ \\
\hline \multirow{5}{*}{6} & Strongly Agree & $24 \%$ & $50 \%$ \\
\hline & Agree & $26 \%$ & $29 \%$ \\
\hline & Undecided & $18 \%$ & $16 \%$ \\
\hline & Disagree & $11 \%$ & $0 \%$ \\
\hline & Strongly Disagree & $21 \%$ & $5 \%$ \\
\hline \multirow{5}{*}{7} & Strongly Agree & $42 \%$ & $55 \%$ \\
\hline & Agree & $24 \%$ & $21 \%$ \\
\hline & Undecided & $13 \%$ & $16 \%$ \\
\hline & Disagree & $8 \%$ & $0 \%$ \\
\hline & Strongly Disagree & $13 \%$ & $8 \%$ \\
\hline \multirow{5}{*}{8} & Strongly Agree & $42 \%$ & $84 \%$ \\
\hline & Agree & $21 \%$ & $13 \%$ \\
\hline & Undecided & $24 \%$ & $3 \%$ \\
\hline & Disagree & $5 \%$ & $0 \%$ \\
\hline & Strongly Disagree & $8 \%$ & $0 \%$ \\
\hline
\end{tabular}

Figure 3. Survey question responses. This chart analyzes the student responses from the survey. The students' responses were bases on a scale of strongly agree to strongly disagree. 38 students completed this survey.

\section{Pledge Score Rubric}

\begin{tabular}{|c|c|c|c|}
\hline Category & 3 & 2 & 1 \\
\hline $\begin{array}{l}\text { The student will make a } \\
\text { self-to-text connection } \\
\text { with the discussion topic. }\end{array}$ & $\begin{array}{l}\text { Student made } \\
\text { connection to topic } \\
\text { and expanded with } \\
\text { their own thoughts }\end{array}$ & $\begin{array}{l}\text { Student made } \\
\text { connection to topic }\end{array}$ & $\begin{array}{l}\text { Student made no } \\
\text { connection to the topic }\end{array}$ \\
\hline $\begin{array}{l}\text { The student will include } \\
\text { supporting details to } \\
\text { expand their idea. }\end{array}$ & $\begin{array}{l}\text { Student included } 2 \\
\text { details }\end{array}$ & $\begin{array}{l}\text { Student included } 1 \\
\text { detail }\end{array}$ & $\begin{array}{l}\text { Student included no } \\
\text { details }\end{array}$ \\
\hline $\begin{array}{l}\text { The student will use } \\
\text { evidence from the lesson to } \\
\text { support their pledge. }\end{array}$ & $\begin{array}{l}\text { Student created well } \\
\text { formulated statement } \\
\text { with evidence from } \\
\text { the lesson }\end{array}$ & $\begin{array}{l}\text { Student created } \\
\text { formulated statement } \\
\text { with little evidence } \\
\text { from the lesson }\end{array}$ & $\begin{array}{l}\text { Student created a } \\
\text { statement with little to } \\
\text { no evidence from the } \\
\text { lesson }\end{array}$ \\
\hline $\begin{array}{l}\text { The student's pledge will } \\
\text { be centered on the main } \\
\text { idea of the lesson. }\end{array}$ & $\begin{array}{l}\text { Information clearly } \\
\text { related to the topic }\end{array}$ & $\begin{array}{l}\text { Information } \\
\text { somewhat related } \\
\text { to the topic }\end{array}$ & $\begin{array}{l}\text { Information did not } \\
\text { relate to the topic }\end{array}$ \\
\hline
\end{tabular}




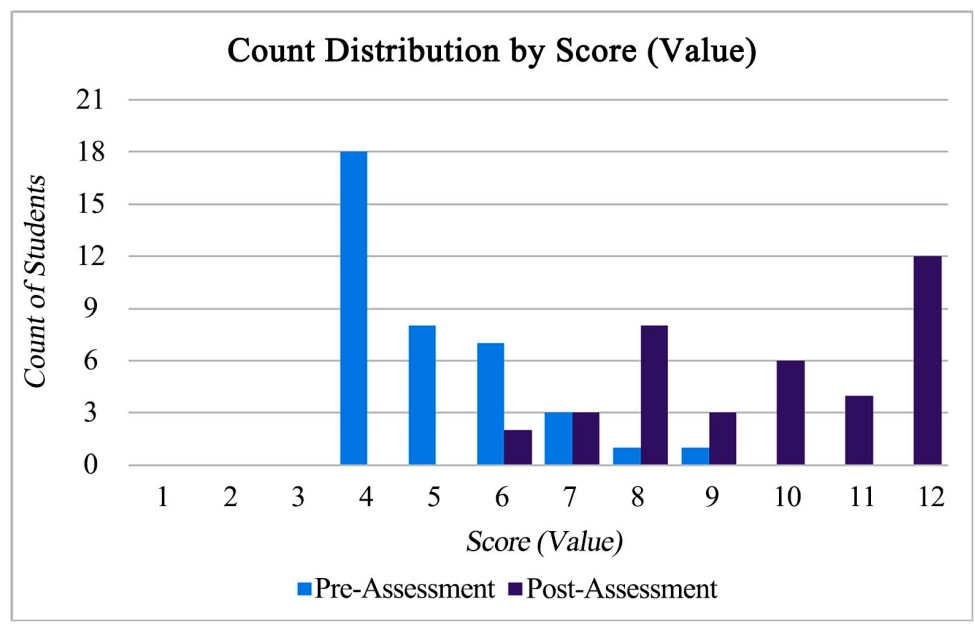

Figure 4. Rubric and Scores of pledge statements. This bar graph illustrated the positive shift in students' pledge scores from pre- to post-test. The students' pledges were assessed using the 12-point rubric shown above the bar graph.

\section{Discussion of Study}

\subsection{Limitations}

A major limitation of this action research study was the sample size. The results of this study were collected from a total population of 38 students. Although results were collected from two different schools, each with a class size of about 15 students, the results were analyzed cumulatively. This small sample size makes it difficult to generalize findings to a larger population. Although this action research study had positive results supporting both our primary and secondary thesis questions, there is not enough data to state that these findings will also occur in other settings.

A second limitation of this action research study was a limited access of different school environments. For example, this study was conducted in two Catholic schools on Long Island, New York. This can be considered as a limited access since Catholic schools can differ from public schools, or even charter schools in a variety of ways. The results of this action research study can not be generalized for all school settings solely based on the results of two different Catholic schools. The results could possibly change based on the region and the common biases and sensitive topics of different areas. Although these results may not be generalized for all settings, other schools and classrooms may have similar positive results to this study.

The last limitation of this action research study is based on longitudinal effects, which relates to the period of time used to conduct this research. These results were found over a period of five weeks and analyzed within a smaller window than other research studies that may be conducted over multiple years. This action research study was confined to the two semesters determined based on Molloy College's schedule, rather than an ongoing timeline where research can be conducted, clarified, and checked multiple times in different settings. 


\subsection{Conclusions}

After analyzing the data collected during this action research study, it was concluded that conducting a talking circle about a sensitive topic does in fact increase participation for elementary aged learners. The positive results of this study have helped to confirm a beneficial strategy to engage students in civil ways to discuss their different views and opinions concerning a variety of sensitive topics. It is the educator's responsibility to create a safe environment where all students feel secure from prejudices, biases, and stereotypes. By conducting a talking circle discussing racism, prejudices, biases, and stereotypes, $66 \%$ of students strongly agreed that they felt safe to share their opinions within the classroom, and $79 \%$ strongly agreed that the talking circle helped to keep them focused and encouraged them to participate. Based on the results of the frequency chart in Figure 1, the educators confirmed that students were more engaged throughout the lesson utilizing a talking circle compared to a basic lesson using direct instruction as the main procedure.

The first sub-question of this action research study inquired if fourth and fifth graders will ask more specific questions about injustice during a talking circle. Through the findings of this study, this sub-question was confirmed that fourth and fifth graders did indeed ask more specific questions about injustice during the post-test. The frequency chart in Figure 1 represents that students asked 17 questions specific to the pre-test discussion and 19 specific questions during the post-test discussion. Although there was not a drastic difference in the number of questions, there was a drastic impact based on participation. Students were more likely to offer opinions, input, and specific comments during the post-lesson, compared to specifically just questions. The results of the action research study concluded that students raised their hands a total of 178 times during the post-test, compared to during the pre-test where students only raised their hands 51 times. During the post-test, students asked both specific questions and made genuine inferences and connections to the discussion, displaying that the fourth and fifth grade students were engaged and participating in a focused discussion based on the given sensitive topic. These comments and inferences also brought light to other sensitive topics that students may be facing within the classroom. As previously stated in the literature review, these topics offer teachable moments that allow educators to create better pathways for civil discourse and communication within the classroom, which can then be used and applied in the student's everyday discussions. The educators of this action research study will continue to explore and introduce more talking circle discussions based on sensitive topics to develop and pave these pathways with students.

The results of this study have also confirmed that students were encouraged to make statements of change as a result of the talking circle discussion. This sub question was supported based on the results of the student pledges, which offered students the opportunity to reflect upon their experience throughout both the pre- and post-lesson. Students were given two opportunities to create statements of change, once after the pre-lesson and again after the post-lesson. Ex- 
amples of these student pledges can be seen in Figures 5-7. These examples illustrate the clear difference between the pre- and post-test pledges.
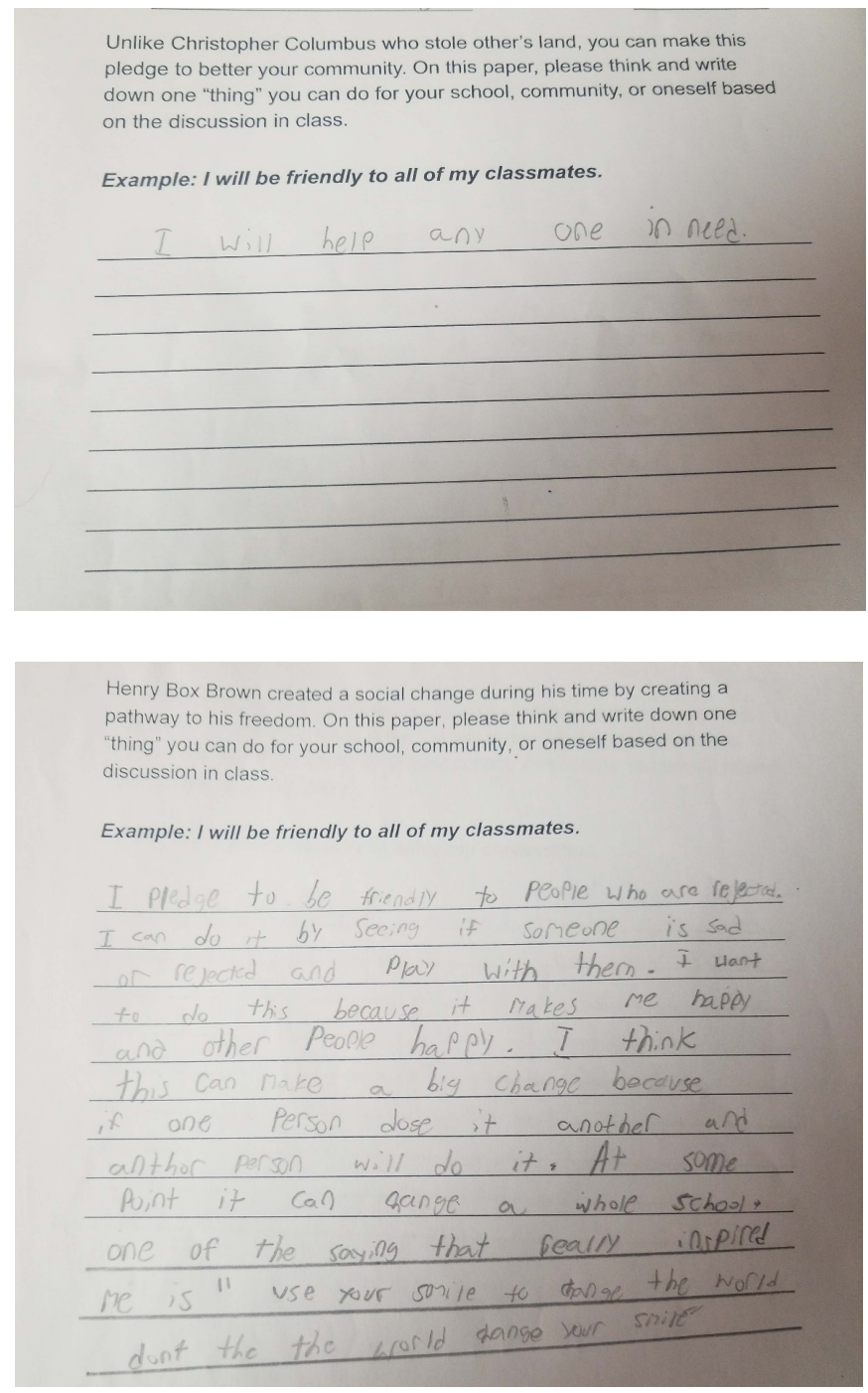

Figure 5. Student A response to prompt in the pretest condition and response in the post test condition following the talking circle strategy.

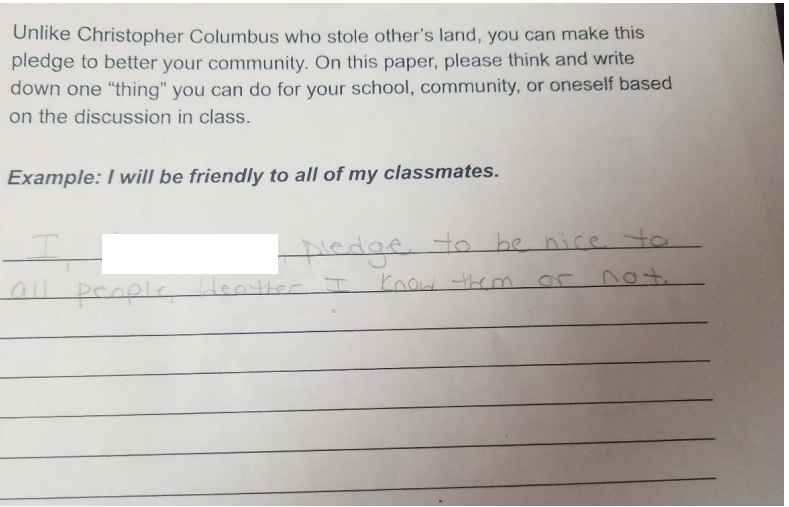

Figure 6. Student B response during the pretest condition. 


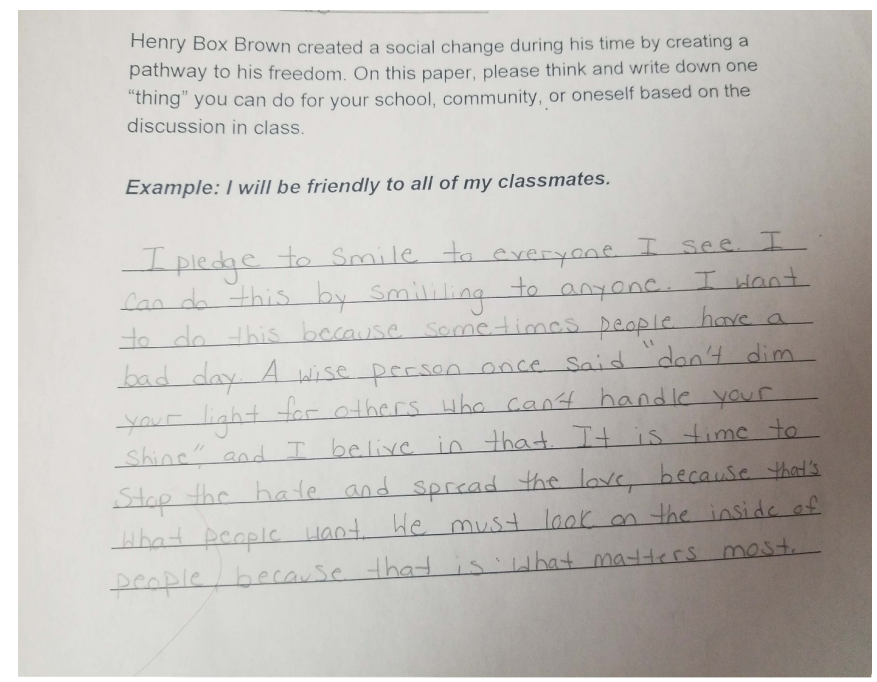

Figure 7. Student B response in the post test condition.

As seen in the teacher reflections in Figure 8 and Figure 9, both educators reported that students made repetitive, in genuine statements of change after the pre-lesson discussion about Columbus Day. Students wrote minimum details, and did not elaborate or share any emotional connection to their pledges. After the talking circle in the post-lesson discussing prejudice, racism, and stereotypes, students constructed emotional, detailed statements of change, and chose to include components of how they plan to accomplish these goals. Students appeared motivated to positively impact their class and community. Each class ended with students discussing positive changes they could make in their school community to spread kindness, fairness, and support. When comparing the student's pledges based on a 12-point rubric, there was a drastic positive shift in both students' grades, as well as range of self-connections made in the post-test pledges. As seen in Figure 5, Student A only wrote one, brief sentence as their pledge in the pre-test, but later wrote a lengthy, detailed pledge about how they planned to make a positive impact on their community in the post-test. The student even made a self-connection to quotes and details shared throughout the class discussion. These results were also supported by other student samples included in Figure 6 and Figure 7.

The last sub question of this action research study inquired if a talking circle could eliminate the fear of being considered racist during a class discussion on a sensitive topic by the teacher. As previously stated in the literature review, educators commonly fear rejection, tension, and offending others based on sensitive topics. The results of this study concluded that the use of a talking circle when discussing sensitive topics in the classroom considerably decreased the pressure of being considered racist both for the teacher, as well as the students. This was evident in the teacher reflections, which expressed the differences both educators felt from the first lesson to the last lesson used in this study. For example, one teacher wrote in her reflection, "my initial feeling going into the lesson was nervous, but after I felt more confident in myself and that made me feel like 


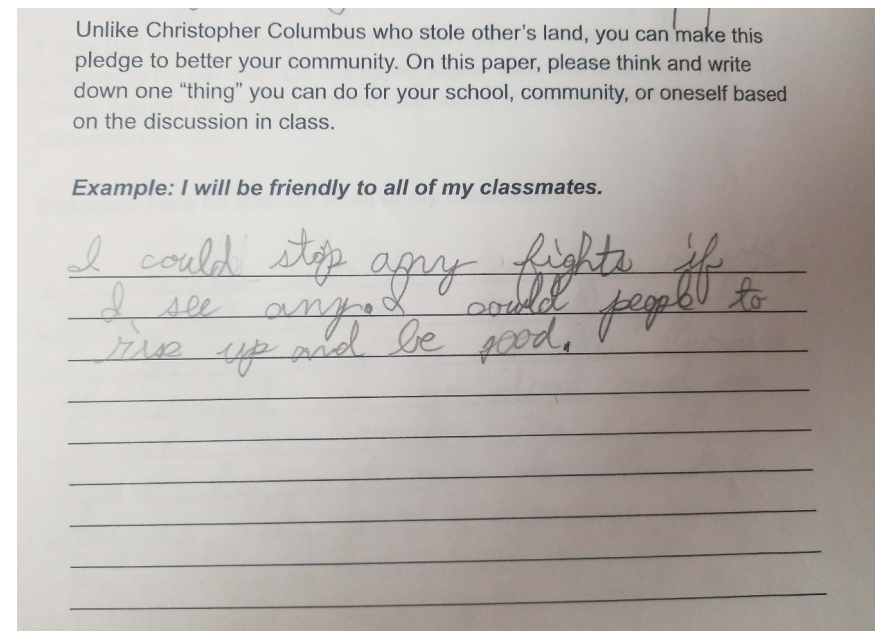

Figure 8. Student $\mathrm{C}$ response to the prompt in the pretest condition.

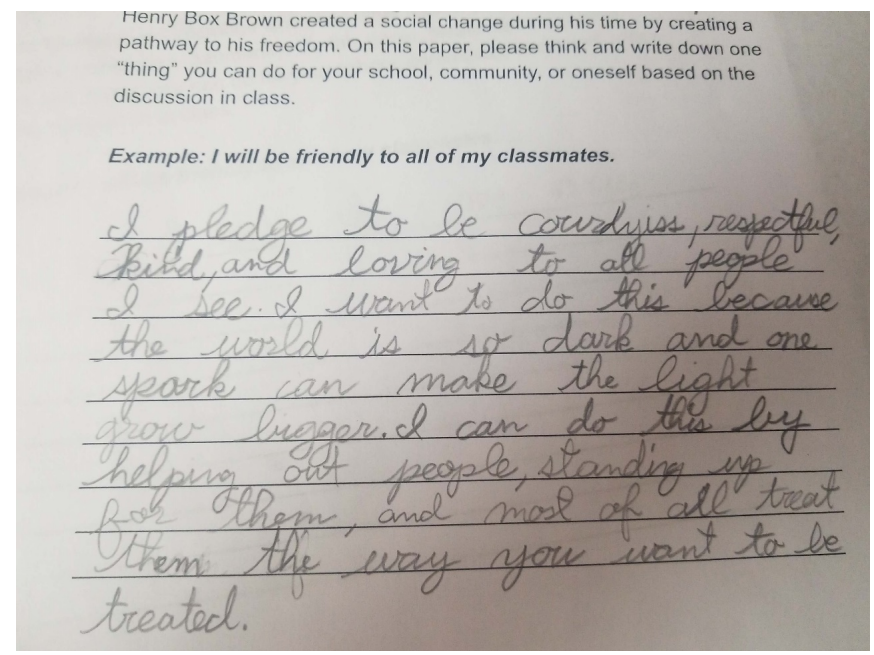

Figure 9. Student $\mathrm{C}$ response to the prompt in the post test condition.

a better teacher for doing this lesson". Another educator from this study stated, "I noticed during this part of the lesson my students were constantly participating. Each student gave more than one emotion, it was truly a magical moment in my classroom. This moment made me feel more comfortable and confident discussing this topic with my class". The results of question four on the student survey also confirm that students also felt safer in the classroom during the talking circle compared to the lesson utilizing direct instruction.

\section{Teacher 1. Reflections of Lessons during the Pretest and Post Test Phase}

During the pretest lesson, which was direct instruction, I felt a disconnection from my students. I first asked the students if they had any prior knowledge of Columbus Day, the students answered with the general input of the topic. We then watched a video based on Christopher Columbus. When asking them questions based on the video, my students were barely active and appeared sluggish. I found it extremely difficult to hold a discussion on the topic with my students because of the lack of motivation in their actions and answers. The students were 
then asked to complete the assessments based on the teacher centered lesson. Students expressed both verbally and through their survey that they felt disconnected from the information and at times bored using this classroom strategy during the lesson. Students' opinions appeared to reflect the teacher's opinion rather than their own personal thoughts. Their pledges were also very simple and not relevant to the prompt. The pledges were repetitive and did not exhibit creativity and genuine thoughts.

\section{Post Test Lesson}

During the post-lesson I wanted to make sure the lesson was engaging as well as informational. To achieve this, I created a talking circle rather than having the students in rows again. I found this to be a positive change based on their assessment results. During the student-centered lesson, all of the students were asked to take part in a See, Think, Wonder based on the front cover of "Henry Box Brown". I thought this as an opening activity was a great start to the lesson. While reading the story, every couple of pages I'd stop and ask the students to describe the emotions happening on the page, I then wrote the emotions on the board. I noticed during this part of the lesson that my students were constantly participating; each student gave more than one emotion, it truly was a magical moment in my classroom. This moment made me feel more comfortable and confident discussing this topic with my class. This strategy was a helpful visual for the talking circle discussion, which was focused around racism, prejudice, and biases. After the discussion we focused on the negative emotions on the board. I thought it was important for the students to visually see the hurt and pain that racism, prejudice, and biases bring to not just a discussion, but to the reality of our world today. To further this conversation, I had my students think of ways to bring equality and love into our school and communities. When they said their ideas, they were able to cross out one of the negative emotions. This part of the lesson I found was extremely powerful, again every student was participating and giving such strong content to their positive ways. When wrapping up the lesson, the students had to create a pledge based on what they learned in class and how to bring this lesson into their communities. Comparing the post-lesson pledges to the pre-lesson pledges, I could tell that the students truly grasped what was being taught. Based on the evidence of the assessments from the post-lesson, the student-centered lesson was much more successful than the teacher centered lesson.

\section{Teacher 2. Reflections of Pretest and Post Test Lessons}

The pre-lesson was teacher centered based learning, which meant students were sitting in rows and listening to my voice. This made it very boring for the students and at times made them feel disengaged from the lesson. It was difficult at times to try to keep the students' attention, because I could tell they were bored and were asking to leave the room multiple times. However, towards the end of the discussion on Christopher Columbus, students were shouting and trying to talk over each other, and not listen to everyone's opinions. The students 
kept calling Christopher Columbus a bad man, and debated why he shouldn't be celebrated. The students continued to discuss this, until I finally calmed them down to review what was learned in the lesson. Then I directed them towards writing their pledge cards and answering their surveys. The students really did not seem to take much interest in the pledge card and seemed to write the first simple thing that came to mind. For the survey, they read the questions and answered to the best of their ability. Being that this was an un-engaging lesson, the students seemed to not care too much and it didn't really seem to stick with them.

As a facilitator of learning, it is hard to keep students engaged in a lesson. I feel as though the lessons need to be focused more on the students teaching each other, rather than me trying to explain everything to them. This lesson in particular was very difficult for me to teach. I did not know how the students would feel about the lesson, or if they would truly understand the big picture. It was also important that I made sure to not share my opinion on the matter and let the students think for themselves. Overall, I felt as though the lesson went well, however, it could have been better. The students were not as engaged as I wanted them to be and I felt that all they took away from this lesson is that Christopher Columbus a bad man, with not much reasoning to back it up. They also did not put too much effort into the pledge card, which made it seem that the lesson was not important to them. This is something for me as a teacher to look into as I continue my teaching career.

\section{Post Test Lesson}

For the post lesson, I was more confident in myself going into the lesson. This lesson was going to be more student-centered, which required them to participate more. For me, I knew what needed to be done and it felt as though the lesson was going to run smoothly and it would be engaging for the students. Having the students in a circle this time, really made a difference. I was able to see all their faces at once and they can see their classmates faces as well, which made it nice for the discussion. As the lesson began, I could feel that it was already better than the first. The students seemed more engaged and were very intent on the story. While reading the story, I could see their eyes widen with disbelief and shock, other times I could see anger in their eyes and at times sadness. It was so interesting from a teacher stand point to see them so engaged and they seemed to genuinely care about the topic being discussed. During the discussions, the students came up with exceptional words and ideas on how to make a change in the world. This continued into them writing out their pledge cards. It was truly a proud teacher moment.

At the end of the lesson, I felt that the students really had a true understanding of the topic and really wanted to make a change in the world. As a teacher, I felt proud of myself and my students for working so hard. This is not an easy topic to teach and it is not an easy topic for students to grasp. My initial feeling going into the lesson was nervous but after I felt more confident in myself and 
that made me feel like a better teacher for doing this lesson. In the future, I feel as though I can handle sensitive topics. The talking circle is a useful strategy that works well when handling sensitive topics and is a strategy that I will be implementing into my classroom from this point forward.

\subsection{Implications}

Based on the results of this action research study, the researchers of this study have decided to continue the use of talking circles within their classrooms to benefit class participation, as well as students' social-emotional development. The use of talking circles have proven to have a positive impact of students' level of participation during lessons and as seen in the results of Figure 3 often offers students a classroom setting where they feel safe to share their opinions and viewpoints of material. The use of this strategy has also decreased negative behaviors such as leaving the room during class discussions, making inappropriate responses when bored, and interrupting teachers while they are talking. This also benefits student's social-emotional development by offering a positive strategy to implement when discussing sensitive topics within the classroom. By creating a positive environment to discuss sensitive topics, students can develop the main principles of civil discourse which they can implement in their daily discussions with peers, friends, family members, and others in their community. By offering students the strategies needed to interact within civil discussions, educators help students become responsible, well-mannered citizens of their community.

As facilitators of learning, the researchers have decided to share the results of this action research study with fellow peers and colleagues in the hope to share awareness to the positive impact talking circles can have on participation within the classroom. The results of this study have suggested that talking circles are a positive outlet for students to discuss sensitive topics, which may vary among grade levels, communities, classrooms, and individuals. This has the potential to increase not only participation within a school, but also allow for more open discussion within classrooms about these sensitive topics students are facing.

\section{Conflicts of Interest}

The authors declare no conflicts of interest regarding the publication of this paper.

\section{References}

[1] The University of Sheffield (2018) Teaching Sensitive or Controversial Topics.

[2] Palmer, E.L. and Louis, K.S. (2017) Talking about Race. Journal of School Leadership, 27, 581-611. https://doi.org/10.1177/105268461702700405

[3] Lorde, A. (2018). https://www.poetryfoundation.org/poets/audre-lorde

[4] Managing Difficult Classroom Discussions. Center for Innovative Teaching and Learning. https://citl.indiana.edu/teaching-resources/diversity-inclusion/managing-difficult-cl assroom-discussions 
[5] Smith, K. (2017) The Impact of Divorce on School-Aged Children. NYU: Steinhardt. https://counseling.steinhardt.nyu.edu/blog/impact-of-divorce-on-students

[6] Spiegler, J. (2014) Teaching about Controversial or Difficult Issues. Morningside Center for Teaching Social Responsibility, New York.

https://www.morningsidecenter.org/teachable-moment/lessons/teaching-about-con troversial-or-difficult-issues

[7] Moore, A.L. and Deshaies, M. (2012) Ten Tips for Facilitating Classroom Discussions on Sensitive Topics. PBS.

[8] Nuffield Foundation (2018) Discussing Sensitive or Controversial Issues.

http://www.nuffieldfoundation.org/science-society/discussing-sensitive-or-controve rsial-issues

[9] Penn State Extension (2017) Facing Sensitive Topics.

https://extension.psu.edu/programs/betterkidcare/early-care/tip-pages/all/facing-se nsitive-topics

[10] Boyes-Watson, C. and Pranis, K. (2015) Circle Forward: Building a Restorative School Community. Living Justice Press, St. Paul.

[11] Umbreit, M. (2003) Talking Circles. Center for Restorative Justice \& Peacemaking, Saint Paul, MN. http://rjp.umn.edu

[12] International Institute for Restorative Practices (2018) Restoring Community. https://www.iirp.edu/defining-restorative/5-2-circles

[13] Jennings, L., Gandarilla, M. and Tan, P.P. (2015) Using the Native American Talking Circle: Experiential Learning on Ethnic and Cultural Diversity of Southern California. Groupwork, 25, 58-77.

[14] Hammerschlag, C.A. (1997) Healing Ceremonies: Creating Personal Rituals for Spiritual, Emotional, Physical, and Mental Health. Perigee Book Indiana University Bloomington, New York.

[15] Krull, S. (2007) Teaching Tips for Successful Circle Times. Excelligence Learning Corporation, Monterey. http://www.earlychildhoodnews.com/earlychildhood/article_print.aspx?ArticleId=5 $\underline{11}$

[16] Rogers, C. (2018) Talking Circles in Fourth Grade.

[17] Shuster, K. (2018) Civil Discourse in the Classroom. Teaching Tolerance. https://www.tolerance.org/magazine/publications/civil-discourse-in-the-classroom

[18] Wright, J. (2014) Participation in the Classroom: Classification and Assessment Techniques. Teaching Innovation Projects, 4, 1-11.

[19] Abdullah, M.Y., Bakar, N.R. and Mahbob, M.H. (2012) Student's Participation in Classroom: What Motivates Them to Speak? Procedia Social and Behavioral Sciences, 51, 516-522. https://doi.org/10.1016/j.sbspro.2012.08.199

[20] St. Onge, J. and Eitel, K. (2017) Increasing Active Participation and Engagement of Students in Circle Formations. Networks. An Online Journal for Teacher Research, 19, Article 7. https://doi.org/10.4148/2470-6353.1014

[21] Harvard Graduate School of Education, Project Zero (2016). http://www.pz.harvard.edu 